\title{
A Statistical Method to Evaluate Fire Risks in Non- residential Buildings in Japan
}

\author{
YUTAKA KOBAYASHI ${ }^{1}$, and HIROYUKI NOZAKI ${ }^{2}$ \\ ${ }^{1}$ Technology Center \\ Taisei Corporation \\ 344-1, Nasecho \\ Totsuka-ku, Yokohama, Japan \\ ${ }^{2}$ Products Development Department \\ Aioi Insurance Company, Ltd. \\ 1-28-1, Ebisu \\ Shibuya-ku, Tokyo, Japan
}

\begin{abstract}
The paper summarizes the background, method and some findings of an on-going study in fire risk assessment for non-residential buildings in Japan. The proposed method bases itself on two sources of information: fire statistics and building inventory statistics. Fire incident records are utilized for obtaining the empirical risk vs. probability of exceedance for a group of buildings of interest, while the probability of fire is specified taking into account the effect of building size, which is represented by alternative indices other than the most straightforward measure, the floor area, because of the lack of relevant construction statistics.
\end{abstract}

KEYWORDS: fire risk assessment, non-residential building, fire incident records, fire statistics

\section{INTRODUCTION}

The objective of the study is to obtain fire risk curves for non-residential buildings so as to form an objective basis for decisions in insurance premium setting, solely based on statistical data that are available in Japan. The first step of our risk analysis is to determine the "group" in which the building to be assessed belongs, in the terms of Japanese fire statistics [1]: property use, structure type, number of stories, etc. Then, the past fire records from the properties matching this definition of group are retrieved, sorted out, and curve-fitted to empirically represent the relation between risk and per-fire probability of exceedance. Due to the limitations of statistics pertaining to existing nonresidential buildings in Japan, it was needed to define a property size-dependent probability of fire as the number of fire incidents divided by alternative building size measures other than floor area. Alternative measures include the number of occupants, number of rooms or beds in case of hotels and hospitals, or any other parameters regarded as closely related to the size of the property. Once obtained, the probability of fire is multiplied by the per-fire probability of exceedance from the step above, thus producing our end result, a fire risk curve, or annual probabilities of exceedance of damage for a typical building within the group.

\section{FRAMEWORK OF THE STATISTICAL METHOD}

The methodology developed here is "statistical" in two manners. The method, first of all, is heavily based on the fire incident information from the past several years that recently 
became available to us electronically. Using the fire records from the specific group of buildings including the object of assessment, the profile of the probability of exceedance "per fire" is derived and curve-fitted, using a nonlinear equation based on HardinDrnevich model [2], against such risk measures of our interest as monetary losses or firedamaged area. Thus, if necessary, the relationship between the risk measure and its perfire probability of exceedance from available statistics can be extrapolated beyond the range where past records exist.

The other "statistical" aspect of the method lies in the definition of the probability of fire. For the reasons shown below, no nationwide inventory information was available in statistics concerning the number, let alone the floor area, of Japanese non-residential buildings [3]. To fill the gap of information, we needed to gather non-construction statistics published by a number of government bodies, to use to represent, not directly the property size in such a term as area, but implicitly the size of the activities to take place on site. The alternative indices include: the number of occupants (employees, students, doctors, etc.), the numbers of hospital beds and hotel rooms, and sales per year generated from the property.

The proposed method of fire risk assessment consists of the following steps:

- Step 1: Retrieval of fire records from buildings "similar" to the object of assessment.

- Step 2: Processing of the records and derivation of "per fire" probability of exceedance of damage.

- $\quad$ Step 3: Evaluation of probability of fire taking into account the size of the building.

- $\quad$ Step 4: Estimation of annual probability of exceedance of fire damage by summing up the results obtained from Steps 2 and 3.

\section{RETRIEVAL OF FIRE DATA}

\section{Property Use, First and Foremost}

The property use of the object of assessment is one of the most important factors we believe to be looked at when gathering fire incident data from the past. Regarding the use of the building of fire origin, Japanese fire statistics [1] include the following information, whose relationship with the building categories of our interest are summarized in Table 1:

- "Fire-Protection Objects" under the Fire Service Law (FSL) in Japan

- $\quad$ Property use for the building of fire origin

- Industrial sector in which the property owner is included

The first two parameters can be related, mostly on a one-on-one or one-on-two basis, with the non-residential building categories that we focus on, while the last entry, a 4digit code notifying the industrial sector in which the owner of the property (which may not necessarily be the building, but could be the portion, or the room, of fire origin inside of the building) is involved, is given whenever the property is used for business purposes. The 4-digit codes included in the fire statistics are virtually the same as those used in other statistics of this nation covering such topics as the economy, energy, labor, welfare, and education. The industry information will be quite helpful especially if further subdivision of the building category is needed. In case of offices only, the industry code becomes "redundant" because whether or not it was an office is readily noticeable by the first two parameters above, while an office will roughly be the same independent of the industry it is involved. For example, a fire on the records may be tracked down to have 
taken place in a sort of hospital by using either the "fire-protection object" classification ((6)-“a”) or the property use code (084) as shown in Table 1 . The industry classification for example for medical institutions below, however, will be the only key to characterize the property more specifically [1]:

- $\quad$ 8811: General Hospitals,

- 8812: Mental Hospitals,

- 8821: General Clinics with less than 20 beds,

- 8822: General Clinics with no beds,

- $\quad$ 8831: Dental Clinics, and so on.

The industry classification offers the most striking usefulness in the manufacturing sector, since the potential fire risk from such properties would be highly dependent, not only on the fact that it is a factory, but also on how and what they produce using what kind of materials on site. The industry codes under the heading of "manufacture" stipulate approximately 300 of its sub-sectors in Japan.

Table 1. Building types and key parameters.

\begin{tabular}{|c|c|c|c|}
\hline Category & $\begin{array}{l}\text { Property at Risk } \\
\text { under FSL }\end{array}$ & Use of Building & Industry Classification \\
\hline Office & 37: Object-(15) & $\begin{array}{l}011 \text { (fixed property use) or 211, 221, etc. } \\
\text { (mixed property use.) }\end{array}$ & The classification is redundant. \\
\hline Retailer & 17: Object-(4) & Included in 021 & $\begin{array}{l}\text { General goods retailers are in } 5411 \\
\text { and } 5499 .\end{array}$ \\
\hline Restaurant & $\begin{array}{l}15 \text { and } 16: \\
\text { Object-(3)-a } \\
\text { and -b }\end{array}$ & $\begin{array}{l}022 \text { as for fixed property use. Hard to } \\
\text { distinguish from a retailer in case of } \\
\text { mixed property use. }\end{array}$ & 6011 to 6131 . \\
\hline Hotel & 18: Object-(5)-a & 082 if fixed property use & 7511 \\
\hline $\begin{array}{l}\text { Medical } \\
\text { Institution }\end{array}$ & 21: Object-(6)-a & 084 if fixed property use & $\begin{array}{l}8811 \text { (general hospitals), } 8812 \\
\text { (mental hospitals), etc. }\end{array}$ \\
\hline School & 24: Object-(7) & 083 if fixed property use & 9111 (elementary school), etc. \\
\hline Factory & 31: Object-(12)-a & 031 if fixed property use & 1211 to 3499 \\
\hline
\end{tabular}

\section{Other Factors to Be Addressed}

Other specifics of the building need to be addressed: especially important are such items as structure type, total floor area, and number of stories of the building of fire origin. These factors are critical, since together with the property use discussed above, they constitute criteria for the level of design-basis safety requirements, not only under the Fire Service Law, but also under the Building Standard Law. Other property- or incidentspecific data fields that may be helpful in segmentizing statistical data include [1]:

- Site Information: Urban or not, distance from a Fire Department, etc.

- Status of Detectors.

- Status of Automatic Extinguishing Systems.

- Time Factors: Time of the day, day of the week, etc.

- Cause of Ignition-Related Items: Heat source, item first ignited, human factors.

- Actions Taken.

It would be fair to state here that there are limitations. For example, the database does not indicate in detail if and how the fire spread beyond the room of origin, nor does it include such a data field as the size of the room [1]. Therefore, there is no way for the method to look into the effectiveness of such a fire-confinement measure as adding a new (or 
replacing with a better) fire-resistant wall to an existing building. The situation will not change as long as the structure of statistics remains the same.

\section{PROBABILITY OF EXCEEDANCE AGAINST MEASURES OF DAMAGE}

\section{What You Can Read from the Data Published}

Japanese fire statistics include a number of fire loss measures covering both human and property losses. When it comes to physical property damages, two measures in the statistics are our topmost interest: the area damaged by flame (in square meters) and the monetary losses (in thousand Yen), both estimated and documented by fire departments. These observations are also published in the "Annual Report on Fires in Japan [4]," which tabulates the number of fires in specific brackets of damage from all sorts of building designated a fire-protection object. The property damage at which each bracket ends happen to be 100, 500, 1000 thousand Yen, etc., and the maximum range covers more than or equal to 50 million Yen. Based on the data, a number of loss probability (probability distribution itself or cumulative/exceeding probabilities) curves were generated on semi- and double-logarithmic scales. Figure 1 presents a double-logarithmic relationship between monetary loss and its probability of exceedance, which is defined here as the ratio of the fires whose damage exceeds the Annual Report-specific bracket boundaries to the overall number of fires. The curve, when rotated minus 90 degrees as in Fig. 1b, appears to begin with a relatively steep slope in the lower-risk, higher-probability region, while they tend to "soften" as the risk increases or as the probability decreases, as if this was a quarter cycle of some hysteretic material models representing the mechanical characteristics of steel, concrete, soils, and others. Motivated by the intuition drawn from these plots, we applied for the release of information on fire statistics, to the Disaster Prevention Information Office, Fire and Disaster Management Agency (FDMA) of Japan, which provided us with full support as well as digital fire incident records accumulated from 1995 to 2001, as of August 2003.

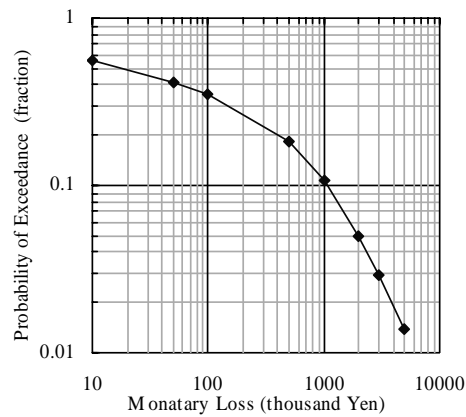

(a) Conventional plot

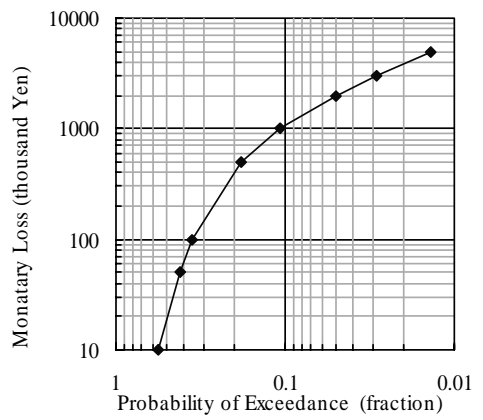

(b) Rotated minus 90 degrees

Fig. 1. Monetary loss curve for fires from all buildings in 1997.

\section{Workflow to Obtain Probability of Exceedance}

After performing some preliminary analyses on the data obtained, it was noticed that, depending on the group of buildings, roughly 10 to $30 \%$ of records in number include a value of zero of monetary losses. In case of damaged area, this ratio sometimes amounts to 70 to $90 \%$. The latter means the probability distribution of damaged area is the highest 
at the value of zero, tends to be the second highest at the unity, 1 square meter, and the third highest at 2 square meters, and so on.

Under the circumstances, we devised a procedure empirically to formulate a fire damage probability of exceedance for specific groups of non-residential buildings, rather than following the conventional procedure for monetary losses, assuming a probability distribution such as truncated lognormal [5]:

- $\quad$ Step 2-1: After defining the group of buildings of interest and fetching data matching the definition in Step 1, count the total record number, $\mathrm{N}_{\text {TOTAL }}$.

- $\quad$ Step 2-2: Sort the records in the ascending order of the damage measure.

- $\quad$ Step 2-3: Renumber the records in ascending order.

- $\quad$ Step 2-4: Count the number of records indicating zero damage ( $\left.\mathrm{N}_{\text {ZERO-DAMAGE }}\right)$.

- Step 2-5: Delete only the zero-damage records. Thus, the number of records including a damage measure of at least unity (1 square meter or 1 thousand yen), $\mathrm{N}_{\text {Damage }}$, is equal to $\mathrm{N}_{\text {Total }}$ minus $\mathrm{N}_{\text {Zero-damage }}$. Damage Ratio $\left(\mathrm{R}_{\mathrm{D}}\right)$ is defined here as the ratio of $\mathrm{N}_{\text {DAMAGE }}$ to $\mathrm{N}_{\text {TOTAL }}$ :

$R_{D}=\frac{N_{\text {DAMAGE }}}{N_{\text {TOTAL }}}$

- $\quad$ Step 2-6: Probability of exceedance for a damage-inducing fire (POED) is first defined as below, for each fire record whose number is denoted with "I":

$\operatorname{POED}(I)=\frac{\left(N_{\text {DAMAGE }}-I+1\right)}{N_{\text {DAMAGE }}}$

POED (I) is the probability for a damage-inducing fire to exceed the level of corresponding damage, D (I). Similarly, probability of exceedance for a fire (POEF), regardless of its damage, is determined by:

$\operatorname{POEF}(I)=R_{D} \times$ POED $(I)$

$$
=\frac{\left(N_{\text {DAMAGE }}-I+1\right)}{N_{\text {TOTAL }}}
$$

For both POEF (I) and POED (I), the dimension is a fraction, and the exceedance probabilities thus defined do not include any unit of time yet.

- $\quad$ Step 2-7: Curve fitting is carried out for double-logarithmic plots of risk (D (I)) versus probability of exceedance (POED (I)) relations, which then can be translated into D (I) vs. POEF (I) relations using Eq. 3. The only model whose goodness-of-fit we have checked so far is a hyperbolic equation (Fig. 2), based on a strain-stress relationship called Hardin-Drnevich model [2], often used in the area of soil dynamics:

$\log (X)=\operatorname{Term}_{\text {NONLINEAR }}+$ Term $_{\text {LINEAR }}$ 
$\operatorname{Term}_{\text {NONLINEAR }}=G_{1} \times \frac{\log (Y)}{1+\log (Y) / \gamma}$

$\operatorname{Term}_{\text {LINEAR }}=G_{2} \times \log (Y)$

X: Measure of Damage (Monetary Loss, or Damaged Area)

Y: Per-Fire Probability of Exceedance for a Damage-Inducing Fire

$\mathrm{G}_{1}$ : Slope of Term NONLINEAR at the onset

$\mathrm{G}_{2}$ : Slope of Term ${ }_{\text {LINEAR }}$

T: Maximum Value for Term NONLINEAR

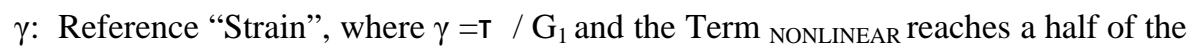
maximum value, $\mathrm{T}$.

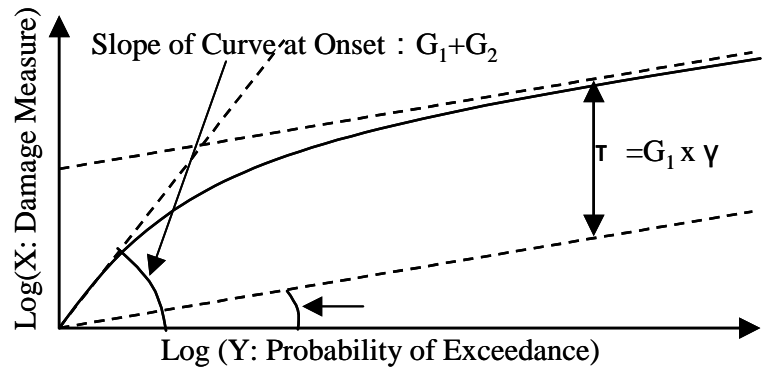

Fig. 2. Notion of the nonlinear model.

\section{Goodness-of-fit of the Nonlinear Model Industry by Industry}

Figure 3 presents POEF versus damaged area relationships for fire-resistant buildings in a number of industry sectors.
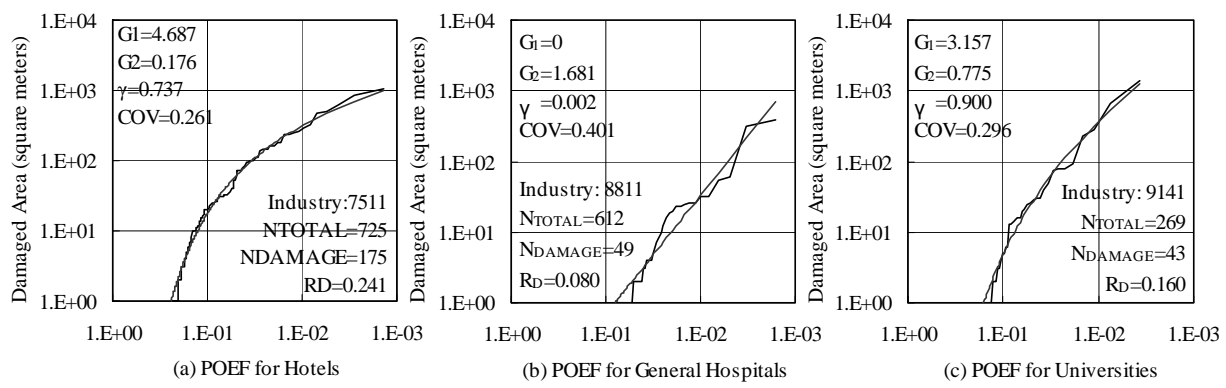

Fig. 3. Goodness-of-fit examples.

Estimates for primary parameters including $G_{1}, G_{2}$ and $Y$ are given in each figure. As a measure of goodness-of-fit, coefficients of variance (COV) are also given on the ratio of observed to HD model estimated damaged area. In general, the above-mentioned nonlinear model fitted the data fairly well with COVs defined above ranging from 0.2 to 
0.3, except for some cases (as shown in Fig. 3b) where the number of relevant records is relatively small (50 non-zero-damage records or less).

\section{Data Subdivision in Accordance to Floor Area and/or Number of Stories}

Fire safety requirements under relevant laws in Japan tend to be more demanding, as a building becomes larger in terms of area and number of stories. It is interesting to look at what influence this imposes on fire risks. Figure 4 compares the floor area and number of stories of the office buildings where a fire took place from 1995 to 2001. The floor area of low-rise office buildings ranges over four to five orders of magnitude, while the variance tends to be smaller as the number of stories gets larger.

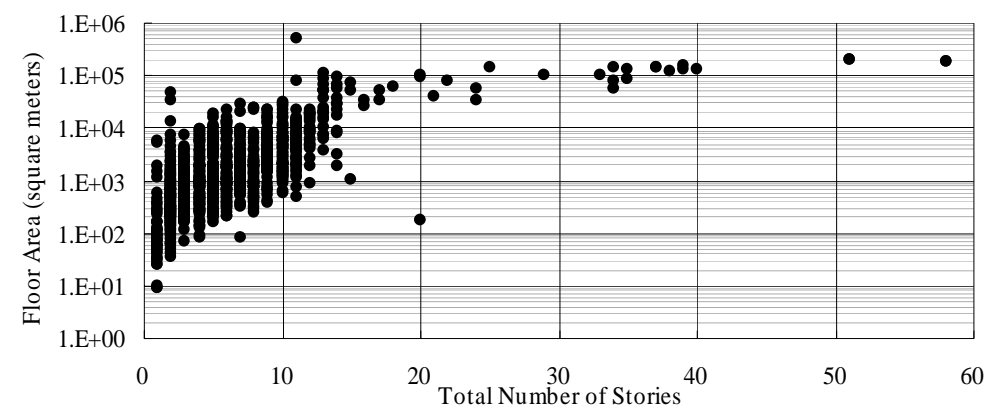

Fig. 4. Floor area vs. number of stories for office buildings.

Based on these observations, the data were categorized into four groups below with roughly the same number of records:

- Group "H": The higher-rise one quarter of the data,

- Group "LL": The largest one third of the rest in terms of floor area,

- Group "LM": The medium-size one third, and

- Group "LS": The smallest one third of the lower-rise three quarters of the data.

POEF's on fire-damaged area are shown in Fig. 5. Per-fire probabilities of exceedance corresponding to the lowest damage (i.e., one square meter by definition) tend to be larger as the building become lower and smaller, while in the lower-probability region, at the level of 1.0E-02 times out of one fire incident or less, the slope of the risk curve appear to depend mainly on the floor area.

\section{PROPERTY SIZE-DEPENDENT PROBABILITY OF FIRE}

\section{Recent Advancement on Utilization of Statistics}

Regarding the probability of fire, a brief review is given on current and recent activities by Keski-Rahkonen and others at VTT in Finland $[6,7,8]$, focusing on the dependence of ignition frequency on the floor area of the building (to be) of fire origin. There are two sources of statistics: a fire statistics database called Pronto is at hand; also available from Statistics Finland are the data of buildings of a variety of categories existing in Finland. The latter not only includes the number and area of the whole buildings in specific residential and non-residential categories but also gives their distributions over classes of floor area. The situation allows directly estimating the following relationships: 
- $\quad$ Number of fires vs. floor area of buildings of fire origin

- Number of buildings vs. floor area of buildings at fire risk

- Thus, ignition frequency vs. floor area of buildings of interest
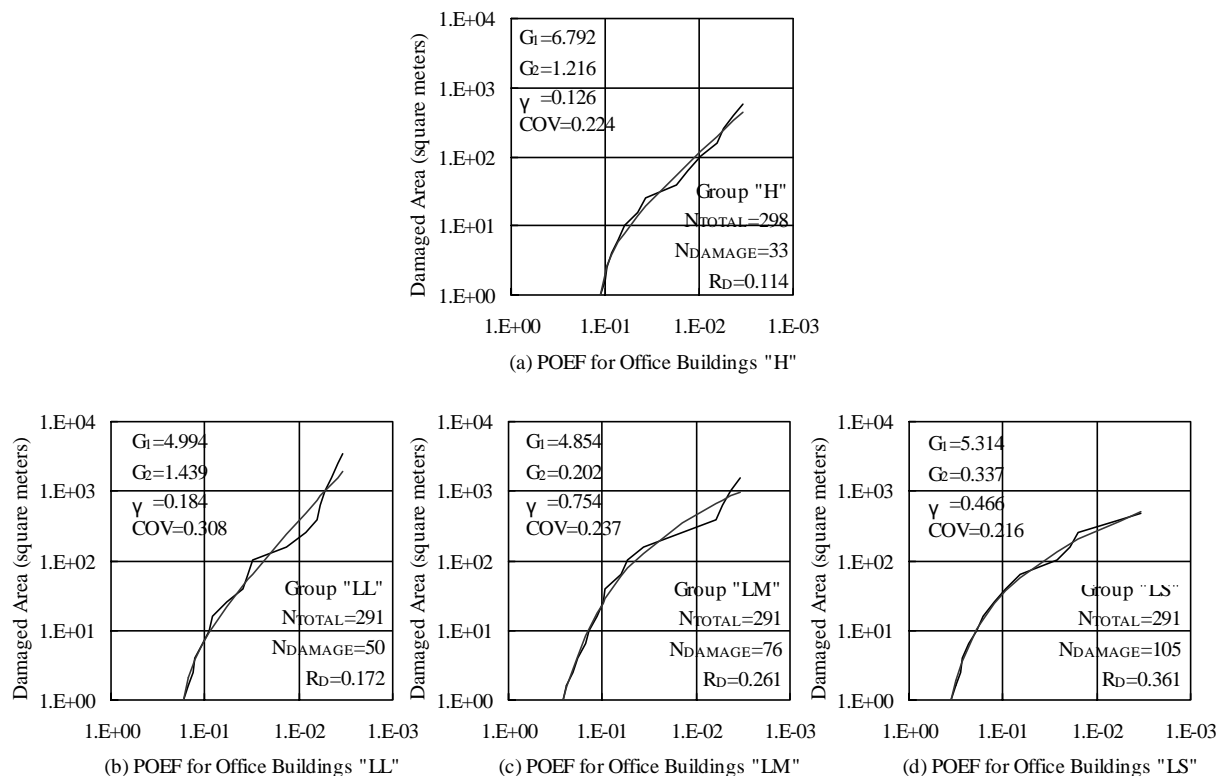

Fig. 5. Per-fire probability of exceedance for various office buildings.

The dependence of ignition frequency thus obtained is of paramount importance in estimating the probability of fire within the framework of fire risk analysis. Furthermore, though the report was not available to us as of conducting the research in 2003, Kati Tillander [8] recently showed that the probabilistic distributions of both buildings of fire and buildings at risk can be fitted well by summing up three components: one Pareto and two lognormal distributions. Using the distributions, Tillander succeeded in explaining some "humps" observed in the relation of ignition frequency against floor area.

\section{Limitations of Construction Statistics in Japan}

Our efforts to find appropriate construction statistics in the same regard lasted until we finally came across the report from a research project entitled "Estimation of Fixed Capital Stocks in Buildings [3]," funded by the Ministry of Land, Infrastructure and Transport (MLIT). The study was aimed at estimating the number and floor area of nonresidential buildings existing in Japan at the beginning of year 2000. The use of buildings was classified into seven categories: offices, stores, factories, warehouses, schools, hospitals, and others. The report is full of tables presenting "estimated" building information sorted by such factors as property use, structure type (wooden or not), ownership (private or public), year of construction, and location on a prefecture-byprefecture basis. The preface to the report appears to tell a lot about the current status of statistics on buildings in Japan: "Though Housing and Land Survey conducted every five years provides detailed information on dwellings, there do not exist any exhaustive statistics for non-residential buildings.” 


\section{An Alternative Procedure to Express Size Dependence}

Though the importance of the MLIT study is unquestionable, the figures found there are not statistics but estimations. The data might or might not be updated in the future. The classification of property use appears quite rough when compared to the in-depthness of the industrial classification in our fire statistics, and it does not include such a category as hotels that we need, nor does it allow us to divide "stores" or tenpo into "retailers" and "restaurants." To get around these drawbacks, an alternative procedure to obtain sizedependent probability of fire was developed as follows. Because of data limitations in Japan, it is not possible to identify the dependence of probability of fire per area on the size of building. The number of fires divided by an alternative size measure estimates average probability of fire. The alternative sources of the "quasi-inventory" information are summarized in Table 2. The Ministry of Economy, Trade and Industry (METI) statistics provide the number of employees for all the sub-sectors on a 4-digit basis in the area of commerce and manufacturing, as well as such economical indices as sales, inventory of products, etc. Other measures on the number of occupants include the numbers of students or teachers for educational facilities, or doctors working at hospitals. These are found in education and health statistics. Furthermore, the statistics of hotel rooms are available from the Ministry of Health, Labor and Welfare. The same ministry compiles and publishes periodically the number of hospital beds. All these measures nationwide may be used as a denominator when estimating our property size-dependent probability of fire.

Table 2. Sources of alternative property size measures.

\begin{tabular}{|l|l|l|l|}
\hline Data Source & Area Covered & Indices of Interest \\
\hline \multirow{2}{*}{ METI $^{\mathrm{a}}$} & Census of Commerce & Wholesale and Retail & $\begin{array}{l}\text { Numbers of establishments and employees, } \\
\text { annual sales, cash wages, products in stock, value } \\
\text { added, etc. }\end{array}$ \\
\cline { 2 - 5 } & Census of Manufacture & Manufacturing & Numbers of establishments, beds, doctors, etc. \\
\hline \multirow{3}{*}{ MHLW $^{\mathrm{b}}$} & $\begin{array}{l}\text { Survey on Medical } \\
\text { Care Institutions }\end{array}$ & Hospitals/Clinics & Neport on Hygiene \\
& Services) & $\begin{array}{l}\text { Hygiene-related } \\
\text { establishments including } \\
\text { food-serving facilities. }\end{array}$ & Numbers of hotels and hotel rooms. \\
\hline MEXT $^{\text {c }}$ & School Basic Survey & $\begin{array}{l}\text { Universities, Schools, } \\
\text { Kindergartens, etc. }\end{array}$ & Numbers of schools, teachers, and students. \\
\hline
\end{tabular}

Alternative information abounds. The next question then is: "Which of the two (or three ore more) is a better (or the best) quasi-size measure in formulating the probability of fire?" To perform a "rule-of-thumb" effectiveness comparison of candidate measures, we produced spreadsheets, which prefecture by prefecture summarize the relationships among number of fire incidents, alternative size measures, and number of sites for comparison. We calculated not only average probability of fire values across the nation but also their standard deviations as well as coefficients of variance by prefecture. Table 3 compares the averages and variance-related indices obtained for five building categories. It should be noted in most cases, the coefficient of variance (COV) is the highest for the probability of fire based on the number of establishments, suggesting the effectiveness of alternative denominators. 
Table 3a. Comparison of candidate denominators.

\begin{tabular}{|c|l|l|l|l|}
\hline \multirow{2}{*}{$\begin{array}{c}\text { Categoty } \\
\text { Studied }\end{array}$} & \multicolumn{1}{|c|}{ Candidate Denominator } & \multicolumn{3}{|c|}{ Probability of Fire } \\
\cline { 3 - 5 } & & Average & $\begin{array}{c}\text { Standard } \\
\text { Deviation }\end{array}$ & COV $^{\mathrm{a}}$ \\
\hline \multirow{4}{*}{$\begin{array}{c}\text { Department Store } \\
\end{array}$} & Number of Establishments & 0.05228 & 0.02292 & 0.43834 \\
\cline { 2 - 5 } & Number of Employees (in 100 persons) & 0.05824 & 0.02394 & 0.41102 \\
\cline { 2 - 5 } & Annual Sales (in 100 million yen) & 0.00213 & 0.00097 & 0.45616 \\
\cline { 2 - 5 } & Sales Floor Area (in square meters) & 0.01333 & 0.00548 & 0.41071 \\
\hline \multirow{2}{*}{$\begin{array}{c}\text { Western Style } \\
\text { Restaurant }\end{array}$} & Number of Enterprises & 0.01251 & 0.00948 & 0.75809 \\
\cline { 2 - 5 } & Number of Employees (in 100 persons) & 0.00048 & 0.00024 & 0.50549 \\
\cline { 2 - 5 } & Annual Sales (in 100 million yen) & 0.08627 & 0.0421 & 0.48796 \\
\hline
\end{tabular}

a: Shaded cells indicate the highest coefficient of variance (COV) in the building category.

Table 3b. Comparison of candidate denominators. [contd.]

\begin{tabular}{|c|l|l|c|c|}
\hline \multirow{2}{*}{$\begin{array}{c}\text { Categoty } \\
\text { Studied }\end{array}$} & \multicolumn{1}{|c|}{ Candidate Denominator } & \multicolumn{3}{|c|}{ Probability of Fire } \\
\cline { 3 - 5 } & & Average & $\begin{array}{c}\text { Standard } \\
\text { Deviation }\end{array}$ & COV $^{\mathrm{a}}$ \\
\hline \multirow{3}{*}{$\begin{array}{l}\text { Hotel/Ryokan } \\
\text { General/Mental } \\
\text { Hospitals }\end{array}$} & Number of Establishments & 0.00257 & 0.00136 & 0.53101 \\
\cline { 2 - 5 } & Number of Rooms (in 100 rooms) & 0.01214 & 0.00322 & 0.26511 \\
\cline { 2 - 5 } & Annual Sales (in 100 million yen) & 0.00215 & 0.00068 & 0.31816 \\
\cline { 2 - 5 } & Number of Establishments & 0.01168 & 0.00554 & 0.47446 \\
\hline \multirow{3}{*}{$\begin{array}{c}\text { Junior Highschool of Beds } \\
\text { Number of Doctors }\end{array}$} & Number of Establishments & 0.00646 & 0.00261 & 0.40314 \\
\cline { 2 - 5 } & Number of Students (in 1000 persons) & 0.01104 & 0.01408 & 0.32292 \\
\cline { 2 - 5 } & Number of Teachers & 0.03282 & 0.01455 & 0.42103 \\
\hline
\end{tabular}

a: Shaded cells indicate the highest coefficient of variance (COV) in the building category.

\section{EXAMPLES OF END RESULTS}

All the findings above have been incorporated into a fire risk assessment system developed in-house at Aioi. Examples of our end results are given in Fig. 6 for four hypothetical groups of department stores. Here, department stores are defined as any fire records whose industry classification is either 5411 or 5499. From 1995 to 2001, there were 1253 fire incidents that took place in fire-resistant buildings matching this definition. The data were then divided into four groups according to the procedure used for Fig. 5 above. The input conditions are provided in Table 4. Median size measures in the table are directly obtained from statistics, while the number of employees representing each category is based on the median floor area of the class, using a uniform employee density of one person per 100 square meters as an assumption.

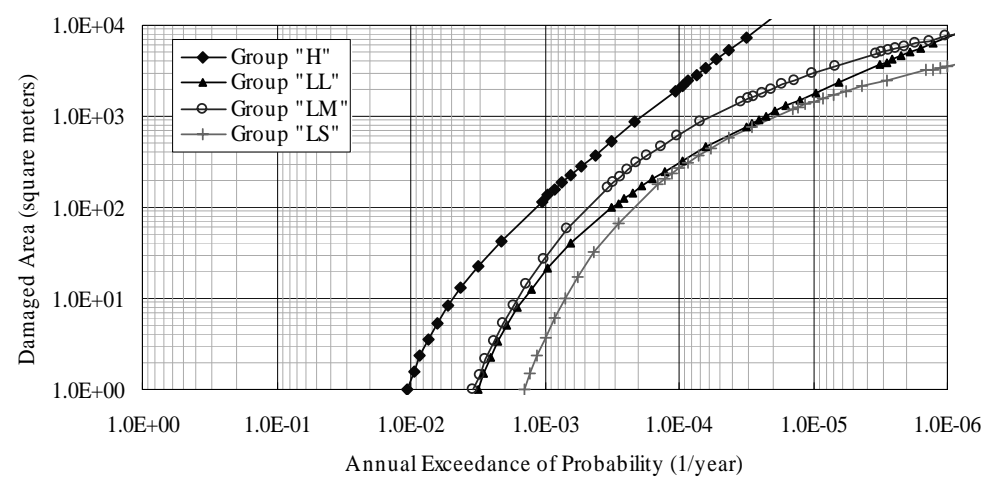

Fig. 6. Risk curves for hypothetical department stores. 
Table 4. Calculation conditions for example risk curves.

\begin{tabular}{|l|r|r|r|}
\hline Classification & Median Floor Area & Median Number of Stories & Number of Employees \\
\hline Group "H" & 36,597 & 10 & 366 \\
\hline Group "LL" & 31,124 & 5 & 311 \\
\hline Group "LM" & 11,239 & 4 & 112 \\
\hline Group "LS" & 2,148 & 2 & 21 \\
\hline
\end{tabular}

\section{CONCLUSIONS}

The findings can be summarized as follows:

- Depending on the group of buildings, roughly 10 to 30\% of records in number include a value of zero of monetary losses in Japanese fire statistics obtained from 1995 to $2001[1,4]$. In case of damaged area, this ratio sometimes amounts to 70 to $90 \%$.

- A nonlinear function based on Hardin-Drnevich model [2] can fit fairly well the relationships of probability of exceedance per damage-inducing fire vs. such damage measures as monetary losses and damaged area, if the records containing a damage measure of zero are excluded.

- Information on existing buildings at fire risk is very much limited in Japan, especially in the non-residential sectors. Hence it is impossible to analyze the dependence of probability of fire per floor area $[6,7,8]$ on the size of a category of buildings.

- However, it is possible to estimate average probability of fire by using such measures as number of on-site employees, annual sales, number of rooms, etc. as a denominator.

- It is possible to obtain a risk curve for a specific type of buildings, by combining the probability of fire and the probability of exceedance per fire as estimated above.

A lot of technical issues also remain to be addressed:

- The performance of the proposed non-linear model appears to be satisfactory. The mechanism behind the nonlinearity formulated as above is yet to be identified.

- Our analysis has been focused on the overall shape of risk curves for various categories of buildings. More focus remains yet to be placed on the upper extreme on the damage measure [5].

We will work on these questions to make improvements to the procedure in the days to come.

\section{ACKNOWLEDGEMENT}

We wish to express our gratitude for their continuous assistance to all the staff members at the Disaster Management Communication Office, FDMA, Ministry of Internal Affairs and Communications. Above all, our thanks are due to Mr. Shigeto Shimada at FDMA for his generously sharing his time for us. His help in the process of data disclosure was crucial to make this type of work possible. This work is a part of a research project for fire safety funded by Aioi Insurance Company, Ltd., and subcontracted to Taisei Corporation in FY 2003. 


\section{REFERENCES}

[1] Handbook for Manual of Fire Reports, ( $8^{\text {th }}$ edition), $4^{\text {th }}$ printing, Tokyo Horei Publishing Co., Ltd., Tokyo, 2003, (in Japanese).

[2] Hardin, B.O., and Drnevich, V.P., "Shear Modulus and Damping in Soils: Design Equations and Curves," Journal of the Soil Mechanics and Foundations Division, ASCE, Vol. 98, NO. GT7, pp. 667-692, (1972).

[3] Estimation of Fixed Capital Stocks in Buildings, Report, The Research Committee, 2002, (in Japanese.)

[4] Annual Report on Fires in Japan, Disaster Prevention Division, FDMA, Ministry of Internal Affairs and Communications, (Published annually, in Japanese).

[5] Ramachandran, G., "Properties of Extreme Order Statistics and their Application to Fire Protection and Insurance Problems,” Fire Safety Journal, 5, pp. 59-76, (1982).

[6] Rahikainen, J., and Keski-Rahkonen, O., "Determination of Ignition Frequency of Fire in Different Premises in Finland," Fire Engineers Journal, 197, pp. 3337, (1998).

[7] Tillander, K., and Keski-Rahkonen, O., "The Ignition Frequency of Structural Fires in Finland 1996-99,” Fire Safety Science - Proceedings of the Seventh International Symposium, 2002, pp.1051-1062.

[8] Tillander, K., "Utilization of Statistics to Assess Fire Risks in Buildings," VTT Publications, No.537, 2004. 